\title{
Terapeuticalização e os dilemas preemptivistas na esfera da saúde pública individualizada
}

\section{Therapeuticalization and preemptive dilemmas within individualized public health}

\author{
Luis David Castiel \\ Fundação Oswaldo Cruz. Departamento de Epidemiologia e Méto- \\ dos Quantitativos em Saúde da Escola Nacional de Saúde Pública. \\ Rio de Janeiro, RJ, Brasil. \\ E-mail: luis.castielळensp.fiocruz.br

\section{Danielle Ribeiro de Moraes} \\ Fundação Oswaldo Cruz. Escola Politécnica de Saúde Joaquim \\ Venâncio. Laboratório de Educação Profissional em Atenção à \\ Saúde. Rio de Janeiro, RJ, Brasil. \\ E-mail: danielleœfiocruz.br \\ Igor Juliano de Paula \\ Prefeitura Municipal de Macaé. Macaé, RJ, Brasil. \\ Fundação Oswaldo Cruz. Escola Nacional de Saúde Pública. Rio \\ de Janeiro, RJ, Brasil. \\ E-mail: ij.paulaœuol.com.br
}

\section{Correspondência}

Rua Leopoldo Bulhões, 1480, 8 andar. Manguinhos, Rio de Janeiro, RJ, Brasil. CEP 21041-210.

\section{Resumo}

Este ensaio pretende abordar o enfoque preemptivo no campo das práticas preventivas em saúde, especialmente quanto à ideia de ataque antecipatório no enfrentamento dos riscos que nos ameaçam. Há perspectivas que apontam para uma suposta imprecisão teórica do conceito "medicalização". Mesmo sendo este ponto de vista passível de discussões, propomos a expressão "terapeuticalização" para designar práticas relacionadas ao cuidado em saúde, com especial ênfase nas tecnologias de automonitoramento da saúde que coletam dados que permitem às pessoas um esquadrinhamento constante de funções biológicas como forma somática de produção de subjetividade. Parece haver uma abrangência que está se ampliando gradualmente para o uso de automonitoramento, que provavelmente deve se expandir, na medida em que um crescente número de organizações e instâncias se dê conta do potencial dos dados produzidos a partir dessas práticas. $\mathrm{O}$ automonitoramento pode ser visto como uma estratégia biopolítica utilitarista que coloca o "si mesmo liberal" como um cidadão responsável, com vontade e capacidade de tomar cuidado de si, de sua felicidade, de seus autointeresses.

Palavras-chave: Prevenção; Preempção; Risco; Automonitoramento; Biopolítica. 


\section{Abstract}

This essay aims to address the preemptive approach in the field of preventive health practices, especially regarding the idea of anticipatory attack in dealing with risks that threaten us. There is a concern that purports that the concept of "medicalization" is affected by lack of theoretical precision. Even being an arguable point of view, we propose the term "therapeuticalization" to describe such practices, with special emphasis on health self-tracking technologies, that collect data that allow people to perform a constant follow-up of biological functions as a somatic self-enterprise. There seems to be a gradual expansion of the use of self-monitoring that tends to grow, as an increasing number of organizations and authorities realize the potential of the data gathered from these practices. Self-monitoring can be seen as an utilitarian biopolitical strategy that put the liberal self as a responsible citizen, willing and able to take care of himself/herself, his/her happiness, his/her self-interests.

Keywords: Prevention; Preemption; Risk; SelfTracking; Biopolitics.

\section{Introdução}

\section{Os sentidos da preempção}

Em geral, é conhecido o significado da palavra “dilema”. Em termos breves, trata-se da condição de escolha imperiosa entre situações nas quais cada uma delas envolve a percepção conflituosa de perdas e ganhos que tornam a decisão penosa e geradora de hesitação por seus supostos desdobramentos. Assim, não há dúvidas sobre o dilema diante das antinomias veiculadas pela perspectiva da preempção no terreno da saúde.

Porém, antes de abordar a temática dos dilemas veiculados pela preempção no contexto sanitário, torna-se necessário aclarar tal vocábulo, cujo uso se mostra incomum no meio sanitário brasileiro. A partir de uma breve busca bibliográfica com a palavra no idioma inglês, localizou-se o artigo de Gorowitz et al. (1998) com o sentido legal referente à esfera do controle das atividades de empresas de armamentos, bebidas alcoólicas e tabaco que causam danos à saúde (neste estudo, à época, a indústria farmacêutica não havia sido incluída neste grupo). Sucintamente, a discussão feita se dirige à regulação de empresas cujas mercadorias produzem riscos à saúde pública e se recusam acatar as determinações sanitárias que tentam normatizar e coibir os problemas de saúde pública relacionados com o uso ou consumo de tais produtos.

No contexto federativo estadunidense, os preceitos legislativos relativos à preempção retiram o foco regulador do nível local e o coloca na esfera dos estados ou do governo federal. Esta configuração assumiu um papel relevante no litígio entre prepostos das empresas envolvidas e dos agentes da saúde pública que têm a função de vigilância sanitária. A proposição preemptiva, assim, faz que a normatização em outra instância, superior ao nível local, assuma preferência em termos de poder legislativo e judiciário sobre o nível equivalente ao local/município (Gorowitz et al., 1998). Portanto, começa a se delinear uma perspectiva da existência de contingências com a finalidade de se adequarem questões de conflitos entre interesses públicos e interesse privados des- 
ta abrangência e significação. Importa ressaltar a necessidade jurídica de que sejam abertos precedentes diante das especificidades dessa ordem de enfrentamentos.

Neste ensaio, temos por pressuposto que o âmbito das ações sanitárias preemptivas relaciona-se a estratégias sanitárias de cunho biopolítico. Na tentativa de produzir reflexões sobre as estratégias preventivas, partimos das acepções e das formas características que as expressões "preempção" e "preemptivo" assumem na língua portuguesa: privilégio na aquisição de algo; antecipação no ato de compra; "algo realizado ou acontecido com anterioridade ao período de tempo supostamente preciso ou cabível para sua realização" (Houaiss, 2009).

Em inglês, enfatiza-se o uso da acepção de caráter bélico em termos de forte ataque preventivo, baseado em um tipo de avaliação através de cálculos algorítmicos de previsibilidade, aliados à vigilância de indícios aparentemente assumidos pelos concorrentes/ adversários, cujas ações devem ser prenunciadas. Em função disto, devem ser desencadeadas ações agressivas de ofensiva sem que ainda haja ocorrido a manifestação do outro. Consiste em um estratagema agonístico, bastante sujeito a erros de avaliação e suposições de suspeita. Obviamente, isso também vale para escaramuças do mundo dos negócios.

No campo da saúde, o termo já é empregado no combate à dor, antes que ela se manifeste, em intervenções médicas, veterinárias e odontológicas. A extirpação das mamas da atriz Angelina Jolie, baseada em dados genéticos familiares, é um exemplo sintomático dessa perspectiva. Da mesma forma, o emprego da "pílula do dia seguinte" contra a possibilidade de ter havido fecundação em uma relação sem proteção anticoncepcional pode ser considerado preemptivo.

$\mathrm{Na}$ busca por uma vida longeva, com vitalidade através de tecnologias de aprimoramento, curiosamente os dois sentidos de preempção se sobrepõem: tanto na acepção de precedência daqueles que podem ter acesso a tais tecnologias como nas alegorias de guerra hiperpreventiva aos efeitos do avanço etário (Castiel, 2014).

Para alguns autores partidários da perspectiva dos life course events - que estuda como eventos precoces da história de vida individual das pessoas influem na ocorrência de doenças -, a assistência à saúde sob o enfoque preemptivo se distingue do preventivo. Este último se apresenta sob o ponto de vista populacional, baseado, por exemplo, em estudos de coorte que estabeleciam os "fatores de risco" para doenças não transmissíveis. Já a abordagem preemptiva se propõe a ser personalizada, padronizando conjuntos populacionais de maior risco em termos genéticos e epigenéticos, por exemplo, grupos de alto risco, preferencialmente a partir de estudos baseados no processamento de enormes quantidades de dados de saúde nas técnicas de data mining e big data. Através do emprego de biomarcadores, tenta-se diagnosticar precocemente enfermidades em estado ainda potencial, com níveis probabilísticos estabelecidos em termos de efetividade da atuação antecipada, antes da eclosão dos sintomas, seja por meio de alterações comportamentais ou por via farmacológica (Imura, 2013).

Percebem-se também discutíveis abordagens preemptivas dirigidas à saúde mental infantil, que procuram detectar antecipadamente manifestações de transtornos em crianças consideradas sob risco, segundo critérios cada vez mais estritos de manifestações tidas como anormais, propostos pelo polêmico Diagnostic Statistical Manual, agora em sua quinta versão. A isto se alia uma forte tendência terapeuticalizante (voltaremos a esta expressão) no campo designado como Psiquiatria do Desenvolvimento, que postula uma prevenção global (a rigor, preemptiva) na saúde mental infantil.

Nesta abordagem, desde um enfoque apresentado como sendo de "saúde pública" a partir de investigações que mostrariam que, amenizando grandes "fatores de risco" (como precariedades socioeconômicas e condições de altos níveis de desgaste emocional em idades muito jovens) e promovendo fatores de proteção, é possível atingir melhores resultados comportamentais (evitando condutas antissociais) ao diminuir o estresse ambiental e dar maior apoio materno (Insel, 2008). Em síntese, parece que tais abordagens se propõem a trilhar um caminho de mitigar sintomas sem considerar as dimensões contextuais que geram o assim chamado "estresse ambiental", além de se poder dizer 
que também parecem operar com naturalizações que cercam as relações de gênero.

0 enfoque preemptivo também se ancora nas proposições baseadas em uma ideia da vida como singularidade biológica. Por exemplo, há abordagens baseadas em uma genotipagem preemptiva para uma medicina personalizada - ao se desenvolver a droga, a dose e a ocasião certas para individualizar o protocolo de tratamento, usa-se a farmacogenômica, configurada por suportes para decisão clínica integrados a registros médicos eletrônicos (Bielinski et al., 2014).

\section{Dilemas preemptivistas e a terapeuticalização}

A expressão “dilema preemptivista” joga com ideias originadas há cerca de 40 anos na tese de Sergio Arouca (2003), que trazia a questão de que o dilema preventivista, de certa forma, reatualizou-se e se ajustou às transformações no campo da saúde ao longo desse período de tempo. Em sua tese de doutorado, realiza abrangente reflexão com a meta de produzir uma crítica da Medicina Preventiva, propondo novos rumos para o âmbito da saúde pública os quais seguiriam a Medicina Social e, depois, a Medicina Coletiva (ainda não havia se institucionalizado o movimento da Saúde Coletiva nesta época). Arouca sustentou a posição de que a Medicina Preventiva era a primeira tentativa de reação no contexto médico a uma configuração de crise mundial no período entre as duas grandes guerras e ao acúmulo de críticas no âmbito da medicina. Considerava, porém, uma perspectiva liberal e civil, que discutia o estatismo que aparecia como alternativa neste terreno. Avançou nos EUA no decorrer de tal época e foi incorporado na América Latina em 1945 como um movimento ideológico, cujo propósito era a mudança da atividade médica através de um profissional baseado em uma nova atitude configurada pelas Escolas Médicas, em função do aumento dos custos da assistência à saúde neste país e como proposta alternativa à intervenção estatal, sustentando a organização liberal da profissão médica e o respectivo poder da Medicina.
Aí estaria a limitação da Medicina Preventiva, já problemática no Brasil da segunda metade dos anos 1970. A tese era a reiteração da impossibilidade da postulação preventivista em lidar com os problemas da saúde pública, porque não enfrentava o âmago do problema: o poder médico e a ênfase individualizante e financeira da saúde. Não colocava em xeque as desigualdades sociais produzidas pela mesma estrutura das quais provinham os problemas do campo médico. A viabilidade daquele projeto no interior do modelo capitalista vigente era nula, e cabiam proposições alternativas a ele, que incidiam na crítica da estrutura social geradora de iniquidades e pela ultrapassagem do preventivismo - útil até certo ponto (especialmente pelo seu papel na configuração de um campo crítico no interior da Medicina), mas insatisfatório ${ }^{1}$.

Diprose (2008), ao discutir as tecnologias biopolíticas da prevenção, assinala um dos problemas centrais desta abordagem: em vez de encarar um evento ameaçador à saúde como próprio ao contexto, sua ocorrência é ampliada como referência padronizada de situações de ameaça à saúde/segurança das populações (cada vez mais questões de saúde se configuram como problemas de segurança) e deve ser tratada preemptivamente. E essa ideia também é extrapolada para a segurança econômica. Ao mesmo tempo, é conferido à medicina papel essencial numa formulação autoritária que coloca a responsabilidade para a saúde e segurança da população sob a tutela do indivíduo e da família na esfera privada. Trata-se de uma tendência ampliada que demoniza e infantiliza grupos populacionais que são acusados de fracassar em acalentar uma imagem sustentada de forma biopolítica para a construção de uma concepção idealizada de si mesmo no futuro a partir de um imaginário médico-moral.

Este imaginário médico-moral conduz à gestão do medo ("riscos") que se configura como uma modelagem da vida e conduta dos corpos. Este modo de pensar leva a dinâmicas das políticas de redução dos danos (e do envelhecimento como um dano), através de medidas preemptivas de controle técnico para a saúde/segurança/ambiente que pretendem

Disponível em: <http://www.memoriasocial.pro.br/linhas/arouca/desdobramentos/olegado.htm>. Acesso em: 1 nov. 2014. 
-predeterminar e proteger o planeta, nações, grupos e indivíduos da imprevisibilidade do futuro, da vida e da ideia de "agência" humana. Isso sem um diagnóstico mínimo e razoavelmente consensual (se é que isto é viável) do que seja o presente atual e seu tecnocapitalismo globalizado com seus paradoxos e contradições não explicitados - tratar o futuro como refém do presente, o que demanda policiar o futuro antecipadamente para que não escape deste presente - esta é a fonte do dilema preemptivista essencial, se podemos assim expressá-lo.

É inevitável trazer à cena que a relação do enfoque preemptivo na saúde possui relações muito próximas com o processo conhecido como "medicalização". Não cabe a este texto aprofundar as intricações das discussões sobre tal conceito. Importa, sim, esclarecer que, segundo Zorzanelli et al. (2014), o conceito apresentaria diferentes sentidos que podem trazer "perda de precisão que retiraria do conceito sua possível utilidade teórica” (Zorzanelli; Ortega; Bezerra-Júnior, 2014, p.1859).

Ora, são inegáveis por parte dos citados autores os méritos dos esforços em tipificar as variações sobre o conceito de medicalização durante um pouco mais de meio século (1950-2010) diante da apregoada imprecisão da expressão. Eles, assim, enfatizam alguns dos sentidos possíveis do termo e os colocam aparentemente num mesmo plano analítico - algo passível de debate, sem atentar para as possíveis distinções analíticas das proposições, quiçá propiciadas pela tematização da questão baseada em periodizações cronológicas.

Assim, o conceito pode se referir a: estratégias abrangentes de sanitarização, tal como é tematizado pela discussão das práticas normativas e disciplinares a partir de Foucault, tanto no nível das medidas públicas do Estado no controle e produção de dados médico-epidemiológicos e indistinção quanto aos limites da incidência da medicina perante a produção de saberes sobre os corpos humanos; transformação de condições encaradas como desviantes em enfermidades - práticas de controle e autoritarismo da medicina. De certa forma, pode-se cogitar que todos esses itens se tornam aspectos ou variantes da primeira perspectiva histórica, sob a perspectiva biopolítica de análise estratégica do poder. A diferença recai em um aspecto considerado favorável: a atuação de agentes exteriores ao campo médico demandando respostas médicas a suas afecções, como no caso de ativistas em relação ao tratamento do HIV-AIDS.

Ora, aqui, mesmo admitindo a pertinência da ação ativista como manifestação do que Foucault chamaria de contraconduta como reação ao poder estabelecido (Foucault, 2008), ainda pode-se encarar, de alguma forma, que estaríamos sob a égide do que Fassin (2012) chama de razão humanitária. Ora, é preciso pensar que os fenômenos biopolíticos sempre têm uma dimensão de economia moral. Moralidade aqui é entendida não como a distinção entre certo e errado, mas do desenvolvimento de normas num dado contexto histórico e geográfico.

A inclusão da dimensão moral amplia a análise política. Há dois aspectos dessa dimensão: 1) as questões de vida e longevidade, saúde e doença não podem ser separadas daquelas da iniquidade social; 2) para além dos aspectos referentes aos diferentes gradientes de longevidade e adoecimento entre ricos e pobres, dominadores e dominados, há uma relação entre corpo e Estado que implica um governo de corpos que organiza a saúde e a integridade corpórea como valores centrais. Aqueles que não devem se deixar morrer, sob o ponto de vista da biolegitimidade são tratados com a razão humanitária - um princípio moral que faz que a vida biológica até transite pela arena política, mas admitindo seu vínculo humanitário que assume uma autoridade vigorosa. A conexão desta lógica com a integridade biológica levou à proliferação de medidas sociopolíticas, programas e políticas públicas. Assim, isso passa a ser uma questão de gestão securitária. Excluídos e/ou desviantes que sofrem física e mentalmente, afetados por pobreza material e exclusão social são cada vez mais considerados vítimas, corpos que sofrem e precisam de atenção à saúde.

Mas essa lógica é ambivalente. Se por um lado, há aparente preocupação por cuidado e compaixão, há a hibridização de problemas políticos com questões morais e de saúde, trazendo-a para o campo humanitário, apagando as consequências funestas do sistema capitalista/colonial. O humanitarismo possui essa propriedade: a de ilusoriamente compatibilizar as contradições deste mundo, tornando o intolerável em 
termos de sua produção de injustiças algo suportável. Não é absurdo cogitar que a expressão "medicalização" pode permitir, em função de sua imprecisão teórica que alguns autores comecem a relativizar, em alguns casos, com uma aparente benevolência, o papel do poder do complexo médico-industrial, ao considerar que poderia haver uma injusta culpabilização, caso não se considerem seus aspectos humanitários positivos.

Ora, não há como negar a importância da atenção à saúde quanto à existência de terapêuticas farmacológicas. Além disto, é elogiável a ação de agentes/ ativistas fora dos aparatos de poder de reivindicarem atenção a suas necessidades de saúde, algo que também seria designado por "medicalização", mas na vertente de uma suposta resistência ao poder. Porém, aqui se desvirtua a noção de "medicalização" como argumento da crítica à manifestação do poder do complexo médico-industrial e parece surgir um significado destituído desse sentido original. E, assim, fragiliza-se o conceito ao assumir uma conotação retórica referente a um suposto "lado bom" da medicalização.

No entanto, isto não parece atenuar a poderosa atuação no interior do neoliberalismo sustentável da indústria farmacêutica, justamente designada por Big Pharma - no contexto neoliberal e suas estratégias mercadológicas identificadas por estudiosos do campo por visarem à proliferação contínua do consumo de medicamentos através de recursos eticamente discutíveis (Elliott, 2010). Por exemplo: a minimização/omissão de efeitos farmacológicos adversos; a aquisição do uso de nomes de pesquisadores (com anuência destes) como autores de artigos escritos por ghostwriters da própria indústria; a realização de dispendiosos ensaios clínicos com resultados que legitimam a inclusão de resultados favoráveis, enviesando metanálises ao evitar a publicação de resultados desfavoráveis; reforçar a utilização abusiva de órteses e próteses, práticas de oferecer viagens, refeições, financiamento para eventos, brindes vários, entre outros agrados e lembranças que seduzem médicos, farmacêuticos e inclusive bioeticistas.

Sabe-se que os pesquisadores dessas empresas desenvolvem novas drogas com uma série de efeitos fisiológicos, nenhum altamente benéfico. Este fenômeno costuma fazer parte destacada do que pode também ser designado por "medicalização". Elliott (2010) enfatiza que a medicina já foi encarada como uma profissão, não como um negócio. Hoje os empreendimentos médicos são enormes, e é duro admitir que o código de confiança implícito entre médicos, pacientes, pesquisadores e sujeitos de pesquisa não está mais assegurado. Inclusive, está documentado que pesquisadores da indústria farmacêutica elaboram uma nova droga e, conforme seu espectro de efeitos farmacológicos, profissionais do marketing da empresa devem vinculá-la ao tratamento de determinadas afecções e promover seu uso aos médicos como o tratamento "mais indicado". Isto pode até implicar em encontrar uma doença incomum cujas respectivas fronteiras possam ser expandidas para incluir mais pacientes ou redefinir aspectos desagradáveis da vida cotidiana como patologia médica (por exemplo: a distimia que tem o mau humor como sintoma).

Ainda assim, não é indiscutível a efetividade da dimensão da tecnomedicina atual. E, ao mesmo tempo, ela tem deixado a desejar com suas estratégias prescritivas de marketing (eventualmente enfatizando aspectos preemptivos) que se aliam a certas práticas de outros campos vinculados à saúde, como: nutrição (o alimento saudável como uma forma de medicamento), odontologia (com sua ênfase em termos de produtos e intervenções estéticas), fisioterápicas (dependendo da proposta clínica, se subsidiária ou não de ditames médicos neoliberais), em certas vertentes da psicologia e nas neurociências (para estimular a ideia cognitiva de autocontrole e evitar comportamentos de risco) e educação física (a atividade física como prática corporal compulsória preventiva de riscos, extensiva a todas as pessoas, independente do estabelecimento específico dos riscos individuais).

Tampouco parece apropriado designar como healthicization (ou algum termo traduzido para o português) as práticas hiperpreventivas relativas aos chamados comportamentos de estilo de vida saudável. Elas são construídas a partir de conhecimentos médicos - medicalizadoras, portanto. Talvez ficassem mais bem subsumidas sob a expressão "terapeuticalização" (agradece-se aqui a sugestão 
de Gustavo Correa da Matta na elaboração desta expressão). Pois, no limite, tornam-se metas de gestão da vida como fenômeno biológico configuradas por noções de risco propaladas por mensagens normativas de porta-vozes da prudência, moderação e temperança em nome da vida saudavelmente regrada. $\mathrm{Ou}$, ainda, determinadas por meios diagnósticos médico-laboratoriais (que, por exemplo, levam ao tratamento medicamentoso com estatinas em função de alterações dislipidêmicas já vistas como pré-patologia e também diante das alterações de valores numéricos definidores de estados sob risco, como a pré-hipertensão, a pré-diabetes e a osteoporose). Esses "diagnósticos de risco" deveriam ser assumidos por aqueles que eventualmente venham a portá-los, gerando, conforme os casos, formas de tratamento preventivo/preemptivo visando à manutenção de saúde e da busca da longevidade - para aqueles que possam arcar com seus custos.

Aliás, queremos crer que o termo "terapeuticalização" (subsumindo, implicitamente, a dimensão diagnóstica) poderia lidar melhor com o panorama dominante em geral das práticas preemptivas medicamente definidas. E, ainda, haveria a vantagem de abordar outras práticas de saúde extramédicas. Ao mesmo tempo, evitaria os supostos problemas da suposta imprecisão conceitual da medicalização.

No caso da medicina, há preocupações crescentes com os efeitos adversos dos sobrediagnósticos e sobretratamentos em pacientes que são considerados casos brandos ou moderados. Alguns chamam, com boas intenções de proteger aos pacientes dos riscos de iatrogenia, de "prevenção quaternária". Esse termo foi concebido por Jamoulle ${ }^{2}$, médico de família belga que assim a definiu: "ação tomada para identificar o paciente sob risco de sobremedicalização para protegê-lo de nova invasão médica e sugerir intervenções que sejam eticamente aceitáveis" [grifos nossos]. Aliás, nesse ponto, será que se torna sintomático o uso do termo "sobremedicalização" para permanecer na crítica aos abusos do chamado complexo-médico-industrial?

Ademais, a expressão prevenção quaternária pode apresentar também aspectos discutíveis, apesar de seus méritos na crítica aos abusos “sobremedicalizadores" potencialmente iatrogênicos na promoção da saúde, prevenção e detecção precoce de doenças. Dá a impressão de ter se aninhado quase como um corpo um tanto estranho aos "níveis de prevenção" de Leavell e Clark dos anos 1960 e da "história natural da doença", ainda validando categorias criticadas desde os anos 1970 pelo seu funcionalismo descontextualizado, reatualizando uma discussão antiga, supostamente anacrônica por não tratar da "determinação social da doença" e sem introduzir nenhum enfoque biopolítico à questão.

Welch (2011) indica vários elementos que intervêm nesses referidos casos de iatrogenia e em intervenções desnecessárias capazes de provocar elevação de condições ansiosas e sofrimentos aos pacientes. As alterações nos valores nas medidas de pressão arterial, dislipidemias, glicemia, osteoporose; exames detalhados de imagem passíveis de dificuldades de interpretação são potencialmente capazes de conduzir a mais exames, monitoramento de diversos tipos de neoplasias e de problemas de gravidez. Conforme Welch, a gênese desses casos é atribuível tanto aos médicos e pacientes que confiam na capacidade de diagnósticos preemptivos de riscos à saúde, como se deve à atuação dos interesses lucrativos do aparato médico-industrial e sua ênfase intervencionista em nome da detecção e da terapêutica precoce.

Cabe ainda um comentário sobre "terapeuticalização", um termo muito pouco encontrado numa rápida pesquisa na rede. Assim, foi possível obter para therapeuticalization três entradas pelo Google Scholar em 4 de novembro de 2014, variando em temáticas (duas menções a trabalhos sobre cultura de consumo e uma em um PDF com documentos sobre a educação de adultos), e sete entradas no Google três delas repetindo as entradas do Google Scholar sobre uma mesma citação em diferentes obras: um artigo de Lund (1996) e um repetindo o documento sobre educação de adultos (Mader, 1992).

Das quatro restantes: 1 ) um projeto de pesquisa português sobre trajetórias de consumo e aprimo-

2 Disponível em: <http://www.ulb.ac.be/esp/mfsp/quat-en.html>. Acesso em: 1 nov. 2014. 
ramento de desempenho entre jovens de Portugal, mais especificamente no consumo das assim chamadas drogas inteligentes (smart drugs) que atuam na capacidade cognitiva e drogas de estilo de vida (lifestyle drugs) que modificam desempenhos somáticos (Lopes et al., 2014); 2) um portal português de uma agência de projetos; 3 ) um fórum com diálogos entre mágicos 3 ; 4) um fórum de usuários de charutos ${ }^{4}$.

Em buscas realizadas em 8 de novembro de 2014, no buscador Google, não foi encontrado nenhum resultado para terapeuticalización em espanhol.E, em português, apenas repetiu-se o mesmo resultado referente ao número (1), acima da pesquisa no idioma inglês em duas entradas. Ou seja, diferentemente da alta incidência da palavra em diferentes proposições semânticas conceituais de "medicalização", o termo "terapeuticalização" parece apresentar uma interessante falta de proliferação e de contaminações conceituais, o que poderia lhe granjear precisão e utilidade teórica.

\section{As práticas terapeuticalizantes de automonitora- mento na saúde pública individualizada}

Há que se cogitar sobre as repercussões preemptivas na subjetividade autorreferida nos movimentos cada vez mais difundidos de monitoramento reflexivo/automonitoramento denominados Quantified Self/Tecnologia autoquantificada (Calvazara, 2014). Este movimento consiste no uso mais frequente de tecnologia para coletar dados sobre si mesmo. Tais recursos permitem às pessoas autorrastrearem aspectos de suas vidas diárias. Há aplicativos relacionados à saúde vinculados a: consumo de comida; consumo de álcool; abandono de tabagismo; exposição ao sol; saúde mental; saúde sexual; monitoração do sono; controle de variáveis fisiológicas, sensações e indicadores, como: glicose sanguínea, controle de peso, índice de massa corporal, aptidão física, temperatura corporal, ritmo respiratório, leitura de indicadores bioquímicos sanguíneos e de atividade cerebral etc.
Esse monitoramento pretende que os indivíduos aprendam mais sobre si mesmos, e, também pretende ajudá-los a tomar medidas para se tornarem mais saudáveis, de acordo com os criadores do movimento, Gary Wolf e Kevin Kelly5, também editores da revista Wired. Eles são considerados responsáveis pela expressão “autoquantificado”, criada quando conceberam um projeto de seguimento das novas tecnologias de monitoramento. A partir do blog Quantified Self criado em 2007, foi construída uma rede que tem como objetivo atender aos usuários e fabricantes de ferramentas de monitoramento. As pessoas teriam sido capazes de acompanhar seu desempenho nas tarefas diárias de várias maneiras durante anos (por exemplo: anotar a quantidade de calorias ingeridas), mas as novas tecnologias teriam deixado esse processo bem menos complicado, de acordo com Wolf (2014).

O automonitoramento está sendo introduzido em locais de trabalho como parte de programas de bem-estar corporativo. Há casas com sensores digitais smart para monitorar a atividade física de seus habitantes, principalmente idosos. Há programas de promoção da saúde que estão usando dispositivos de monitoração com sensores para gerar dados comunitários com o propósito de que leigos podem ser treinados e equipados para produzir dados científicos ou projetos comunitários. Conceitos como "cidade saudável" e "cidade inteligente" se combinam para gerar a "cidade inteligente e saudável” (inteligente porque saudável e saudável porque inteligente...) (Lupton, 2014). Há aplicativos de smartphones com jogos relacionados à saúde e à aptidão física (exergames). Além disso, pode-se usar big data para gerar percepções sobre epidemias $\left(\right.$ HealthMap ${ }^{6}$ ) e ocorrências de crimes em cidades como Nova York (Ferguson, 2014).

Começa a ocorrer um obscurecimento das fronteiras entre o provimento de atenção em termos de saúde pública e o autocuidado. Seria esta uma prática que poderia ser designada como "autoterapeuti-

3 Disponível em: <http://www.themagiccafe.com/forums/viewtopic.php?topic=417147\&forum=32>. Acesso em: 6 out. 2015 .

4 Disponível em: <http://www.herfersparadise.org/portal/modules.php?name=Forums\&file=viewtopic\&p=1412595\&sid=8ad83219e18db 128a2cf2a58da5d5235>. Acesso em: 6 out. 2015 .

5 Disponível em: <http://quantifiedself.com>. Acesso em: 7 nov. 2014.

6 Disponível em: <http://healthmap.org/pt/>. Acesso em: 6 nov. 2014. 
calização", propiciando mais um novo sentido alternativo para o conceito de "(auto)medicalização"? A promoção da saúde pública por iniciativa individual passa a enfatizar mais ainda a responsabilidade individual e a autodisciplina no ambiente político neoliberal, que se ajusta bem às medidas de austeridade diante das crises financeiras globais. Ainda assim, devemos lembrar que também pode haver iniciativas de ativismo político de comunidades que ultrapassem as perspectivas de controle externo e coletem seus próprios dados para delinearem suas necessidades e demandar ações governamentais diante de condições de transporte e tráfego, dados sobre crime, disposição de lixo, poluição etc.

De todo o modo, Bauman e Lyon se referem ao minipanóptico pessoal sob a forma de tablets e smartphones (Bauman; Lyon, 2014), e a fusão deles - os "phablets". Dessa forma, não é absurdo cogitar em "smartphrones": um tipo de phone/drone inteligente que pretende nos transformar em androides consumidores. Seria um tipo particular de drone simbionte parasitário que voa em nossas roupas durante nossos voos literais e metafóricos. Além de servir como mero telefone e permitir cair nas redes sociais, também podem atuar na conexão vigilante constante entre diretores e empregados, permitir o rastreamento, a compilação e o processamento dos movimentos dos usuários dos impérios “internéticos” cujos serviços são acessíveis aos interessados: Google, Face(trace)book e Amazon.com, que produzem enormes bases de dados e categorizam via big data os algoritmos dos perfis de potenciais consumidores.

Os gestores atuais podem ser muito mais sutis comparados com os antiquados vigilantes mantenedores da rotina laboral. São rastreadores dos movimentos de desejo dos usuários da rede. Mas há os que estão à mercê do banóptico (Bigo, 2008) cuja função estratégica é determinar uma minoria como excluída. E seus três elementos constituem um poder excepcional no âmbito das sociedades liberais: o estado de emergência (que se converte na regra); a seleção (que exclui a certos grupos ou a categorias inteiras de pessoas por seu comportamento social futuro); e normalização dos grupos não excluídos (mediante a crença na livre circulação de bens, capital, informação e pessoas).

Didier Bigo (2008) fala de toda a rede referente às atividades daqueles que ele chama de "gestores da inquietude" (professionals of unease management) - os profissionais da segurança e outros - que são os que estão mais próximos ao dispositivo que controla e vigia os grupos que oferecem "riscos" (como os jovens que faziam "rolezinho" em shoppings de São Paulo em 2013).

Segundo Lupton (2014), muitas pessoas manifestam a impotência diante do poder das grandes empresas da internet para coletar, possuir e usufruir de seus dados pessoais. Algumas vezes, usuários de autorrastreamento concordam com o uso de seus dados pessoais como uma parte inevitável da aceitação dos termos e condições de seus dispositivos, aplicativos móveis e plataformas.

Em outros casos, seus dados podem ser acessados sem seu conhecimento ou consentimento. A segurança de dados disponibilizados em plataformas digitais não é à prova de falhas de segurança. A forma como dados digitais podem ser utilizados por diferentes atores e instâncias não pode ser prevista nem controlada.

À medida que seres humanos se tornam nós em redes na internet, gerando e trocando dados digitais com outros agentes, as práticas de automonitoramento se tornarão inevitáveis para muita gente. Parece haver uma abrangência que está se ampliando gradualmente para o uso de automonitoramento, que provavelmente deve se expandir na medida em que um crescente número de organizações e instâncias se dê conta do potencial dos dados produzidos a partir destas práticas.

$\mathrm{O}$ automonitoramento pode ser visto como uma das estratégias e discursos heterogêneos que colocam o "si mesmo liberal" como um cidadão responsável, com vontade e capacidade de tomar cuidado de si ou de seus autointeresses e bem-estar. 0 neoliberalismo promove a ideia normativa de cidadão que não precisa de coerção para se comportar produtivamente e nos interesses do tecnocapitalismo (Lupton, 2014). 0 "conhece-te a ti mesmo" deixou de ser uma autoanálise de caráter reflexivo em termos psicológicos ("pôr a mão na consciência"), mas passa a ser um esquadrinhamento de funções biológicas como exercício identitário somático. 
A saúde pública vai se tornando um projeto individualizado para aqueles que têm acesso às tecnologias de automonitoramento.

\section{Conclusão}

\section{A felicidade utilitarista}

Um dos problemas das perspectivas apresentadas é o fato da preempção desejada não ter como resolver as vicissitudes da vida e as decorrências em termos de mudanças de expectativas. De fato, não é viável prever as imponderabilidades futuras e os respectivos riscos, mesmo que se amplie de modo gigantesco a capacidade de processamento informático dos dados mediante automonitoramento tratado por técnicas de big data. Assim, coloca-se a questão do processo de decisões gerenciais em função dos riscos serem assumidos sob pressupostos razoavelmente arbitrários em relação ao que se imagina como sendo informações confiáveis de previsão sobre a gênese e o enfrentamento de perigos, agravos e malefícios.

Não há como evitar ocorrências cuja dimensão preditiva sai do esperado e, segundo Nicholas Nassim Taleb (2008), que revelam as restrições do pensamento indutivo e seu engano de abrangência ampliada quanto ao que pode suceder em nosso mundo, que é mais intrincado e submetido ao acaso do que usualmente se cogita; a falta de robustez na possibilidade de achados de estudos retrospectivos sinalizarem com estabilidade e precisão as possibilidades para o futuro; o superdimensionamento de dados apregoados por especialistas e oráculos, ainda mais quando concebem categorias analíticas sem entrar nos méritos de suas premissas.

Em termos esquemáticos, a ética utilitarista designada como "consequencialista" se baseia na noção de que cada indivíduo deve vincular seus interesses pessoais a interesses comuns, de modo que sua ação produza a maior utilidade a todas as pessoas envolvidas nos efeitos da ação. Da mesma forma como cada um desejaria naturalmente a própria felicidade, o bem-estar de todos será um bem para o total dos seres humanos. A boa ação deve ser, logicamente, útil, porém, uma ação moralmente correta deve gerar consequências que se convertam em felicidade (prazer) para as demais pessoas. A propriedade moral de uma ação é avaliada por suas consequências benéficas esperadas. Um modo de avaliá-la é dimensionar a elevação da felicidade (prazer) e a diminuição do sofrimento daqueles que sofrem os resultados de determinada ação, especialmente quanto à gerência da pretendida qualidade das ações, sem levar em conta aspectos estruturais (Orozco, 2009).

O postulado básico do utilitarismo chamado Utilidade/Maior Felicidade, sinaliza que as ações são moralmente corretas quando buscam promover a felicidade, e incorretas quando geram o negativo da felicidade. A aplicação desse postulado traz um cálculo do estado de bem-estar, onde se mensuram aspectos positivos e negativos quanto às diversas possibilidades de rumo de determinadas ações, considerando a medida de satisfação/insatisfação que pode ser esperada de tais ações. 0 referido cálculo deve incluir um grupo de parâmetros para avaliar os graus de satisfação/insatisfação resultantes, em termos de força, durabilidade, graus de evitação de incertezas, sua evolução. Essa aritmética utilitarista se propõe a escolher a ação que seja correta em termos morais de modo a se atingir o mais alto possível nível de felicidade (prazer) para a maior quantidade de gente (Orozco, 2009). Nos tempos atuais, há elementos sugestivos de que a matemática utilitarista se volta para a máxima longevidade com qualidade de vida para todos que a desejem e disponham de recursos de acesso a propostas preemptivas de saúde, mesmo diante de suas ambivalências.

Para Zizek (2006), a ética utilitarista é a ética da não autonomia. Sua ideia real é que não há autonomia de fato. Diante do postulado que procuramos otimizar nosso prazer, este se constitui numa tirania determinante de nossa conduta. A possibilidade de conduzir as pessoas em função da busca da felicidade de cada um ("correndo atrás de seus sonhos etc.”), que deverá ser a felicidade de todos na vida de consumo tecnocapitalista, mostra-nos que tal ideia de felicidade tende a ser algo referente à autossatisfação pessoal, sem o deslocamento subsequente para os demais. Portanto, a noção de 
pessoa autônoma, responsável e livre para decidir o que lhe convém uma vez bem informada se constitui numa montagem jurídica. A função é produzir um ator centrado numa perspectiva de responsabilidade que eventualmente seja punido por suas ações inaceitáveis em busca de sua "felicidade", mas que não é moralmente bom para os outros, em termos utilitaristas do ponto de vista da vida comunal. Entretanto, essa configuração borra a possibilidade de uma avaliação analítica mais criteriosa das circunstâncias sociopolíticas ampliadas dos contextos originários de onde emanam contingências moralmente encaradas como reprováveis.

Enfim, de forma bastante esquemática e alegórica, será cabível imaginar que seremos cada vez mais dirigidos pela produção de subjetividades constituídas por um peculiar grupo de protótipos em função da hiperprevenção terapeuticalizadora e de suas variantes, todos orientados, claro, pelo homo oeconomicus do utilitarismo que estabelece as receitas corretas de busca autônoma da felicidade. Então teremos: homo praeventus (etimologicamente: ação de prevenir advertindo); da evidência, homo evidens (que tem acesso à ciência big data que vai produzir as melhores verdades evidencialistas), da preempção, homo praeempt vus (diante da suspeita de ameaças, (re)agir "cortando o mal” antes dele ter raiz, ou mesmo existir); do autocuidado (de si...), o homo autós cogitatum (aquele que pensa/ que se cuida - com aplicativos etc.).

Mas, do lado de fora, fica o homo residùum, fantasmatizado e excluído pelos gestores da inquietude e o homo a-typicus, que ocupa o lugar do ponto fora da curva (ou da curva fora do ponto), ao perceber o espectro da normalidade normativizada e suas vicissitudes. Um "outliar", se permitem o jogo de palavras no idioma inglês - o que não diz a verdade, do lado de fora - diante das "verdades experimentais" - que provêm do evidencialismo empiricista - seja big data ou não.

\section{Referências}

AROUCA, S. O dilema preventivista: contribuição para a compreensão e crítica da medicina preventiva. São Paulo: Unesp; Rio de Janeiro: Fiocruz, 2003.
BAUMAN, Z.; LYON, D. Vigilância líquida. Rio de Janeiro: Zahar, 2014.

BIELINSKI, S. J. et al. Preemptive genotyping for personalized medicine: design of the right drug, right dose, right time - using genomic data to individualize treatment protocol. Mayo Clinic Proceedings, Rochester, v. 89, n. 1, p. 25-33, 2014.

BIGO, D. Globalized (in) security: the field and the ban-opticon. In: BIGO, D.; TSOUKALA, A. Terror, insecurity and liberty: Iliberal practices of liberal regimes after 9/11. Oxon; New York: Routledge, 2008. p. 10-48.

CALVAZARA, B. O que é a tecnologia autoquantificada? QGA, [S. l.], 6 set. 2013. Disponível em: <http://qga.com.br/ tecnologia/2013/o9/o-que-e-a-tecnologiaautoquantificada>. Acesso em: 7 nov. 2014.

CASTIEL, L. D. Medicina, técnica, ética e os dilemas preemptivistas na saúde. Entrevista a Junges, M. R. e Costa, A. IHU On-line. Revista do Instituto Humanitas Unsinos, São Leopoldo, v. 456, n. 14, p. 18-24, 2014.

DIPROSE, R. Biopolitical technologies of prevention. Health Sociological Review, Sippy Downs, v. 17, n. 2, p. 141-150, 2008.

ELLIOTT, C. White coat, black hat: adventures on the dark side of medicine. Boston: Beacon Press, 2010.

FASSIN, D. Humanitarian reason: a moral history of the present. Berkeley: University of California Press, 2012.

FERGUSON, A. G. Big data policing in the Big Apple. The Huffington Post, [S. 1.], 15 jul. 2014. Disponível em: <http://www.huffingtonpost.com/ andrew-guthrie-ferguson/big-data-policing-inthe_b_5588oog.html>. Acesso em: 6 nov. 2014. FOUCAULT, M. Segurança, território, população. São Paulo: Martins Fontes, 2008.

GOROWITZ, E.; MOSHER, J.; PERTSCHUK, M. Preemption or prevention?: lessons from efforts to control firearms, alcohol, and tobacco. Journal of Public Health Policy, Hants, v. 19, n. 1, p. 36-5o, 1998.

HOUAISS, A. Dicionário Houaiss da língua portuguesa. Rio de Janeiro: Objetiva, 2009. 
IMURA, H. Life course health care and preemptive approach to non-communicable diseases.

Proceedings of the Japan Academy, Ser. B, Physical and Biological Sciences, Tokyo, v. 89, n. 10, p. 462-473, 2013.

INSEL, T. R. From prevention to preemption: a paradigm shift in psychiatry. Psychiatric Times, [S. l.], 1 ago. 2008. Disponível em: <http://www. psychiatrictimes.com/articles/preventionpreemption-paradigm-shift-psychiatry>. Acesso em: 1 nov. 2014.

LOPES, N. M. et al. Therapeutic consumptions of performance among young people: trajectories and information networks. Lisboa: Fundação para a Ciência e a Tecnologia, 2010. Disponível em: <https://alfa.fct.mctes.pt/apoios/projectos/ consulta/vglobal_projecto.phtml.en?idProjecto=1 18073\&idElemConcurso=4222 >. Acesso em: 6 out. 2015 .

LOPES, N. M. et al. Therapeutic consumptions of performance among young people: trajectories and information networks. Lisboa: Centre for Research and Studies in Sociology, 2014. Disponível em: <http://www.cies.iscte.pt/en/ projectos/ficha.jsp?pkid=503>. Acesso em: 6 out. 2015 .

LUND, A. B. Terapeutokratisering af politisk offentlighed. Grus, Kopenhagen, v. 17, n. 49, p. 30-46, 1996.

LUPTON, D. Self-tracking modes: reflexive self-monitoring and data practices. Canberra: [s. n.], 2014. Disponível em: <http://ssrn.com/ abstract $=2483549>$. Acesso em: 6 nov. 2014.
MADER, W. Adult education in the Federal Republic of Germany: scholarly approaches and professional practice. Monographs on comparative and area studies in adult education. Vancouver: Centre for Continuing Education The University of British Columbia, 1992. Disponível em: <http://files.eric.ed.gov/fulltext/ED346306. pdf $>$. Acesso em: 6 out. 2015 .

OROZCO, O. G. El fín de la gerencia pública. Estado, Gobierno, Gestión Pública. Revista Chilena de Administración Pública, Santiago, v. 13, p. 5-22, nov. 2009.

TALEB, N. N. A lógica do cisne negro: o impacto do altamente improvável. Rio de Janeiro: Record, 2008.

WELCH, H. G.; SCHWARTZ, L. M.; WOLOSHIN, S. Overdiagnosed: making people sick in the pursuit of health. Boston: Beacon Press, 2011.

WOLF, G. Even when I'm active, I'm sedentary. Quantified Self, [S. l.], 2 out. 2014. Disponível em: <http://quantifiedself.com/2014/10/even-imactive-im-sedentary/>. Acesso em: 10 nov. 2014.

ZIZEK, S.; DALY, G. Arriscar o impossível: conversas com Zizek. São Paulo: Martins Fontes, 2006.

ZORZANELLI, R. T.; ORTEGA, F.; BEZERRAJÚNIOR, B. Um panorama sobre as variações em torno do conceito de medicalização entre 19502010. Ciência \& Saúde Coletiva, Rio de Janeiro, v. 19, n. 6, p. 1859-1868, 2014.

\section{Contribuição dos autores}

Todos os autores participaram das fases de concepção, elaboração, redação e revisão crítica do texto.

Recebido: $13 / 11 / 2014$

Aprovado: 03/06/2015 